\title{
Haemoglobin level and its clinical impact in a cohort of patients with COPD
}

\author{
C. Cote*, M.D. Zilberberg*, S.H. Mody" ${ }^{\#}$ L.J. Dordelly* and B. Celli"
}

ABSTRACT: Haemoglobin ( $\mathrm{Hb}$ ) abnormalities in chronic obstructive pulmonary disease (COPD) are not well characterised. The present authors investigated the prevalence and association of abnormal $\mathrm{Hb}$ with clinical outcomes.

Analysis of a prospective cohort of stable COPD outpatients $(n=683)$ in a USA Veterans Administration pulmonary clinic was undertaken. Patients were classified as anaemic (Hb $<13 \mathrm{~g} \cdot \mathrm{dL}^{-1}$ ), polycythemic $\left(\mathrm{Hb} \geqslant 17 \mathrm{~g} \cdot \mathrm{dL}^{-1}\right.$ and $\geqslant 15 \mathrm{~g} \cdot \mathrm{dL}^{-1}$ for males and females, respectively) or normal. Demographic characteristics and physiological/functional outcomes were compared between groups. Regression models adjusting for confounders examined the independent association of anaemia with clinical outcomes.

Anaemia was present in 116 (17\%) patients and polycythemia in 40 (6\%). While the only values that differed between polycythemic and nonpolycythemic patients were mean body mass index and $\mathrm{Hb}$, anaemic patients showed a significantly higher modified Medical Research Council dyspnoea scale score (2.8 versus 2.6), lower 6-min walk distance (265 versus $325 \mathrm{~m}$ ) and shorter median survival (49 versus 74 months) than nonanaemic patients. In regression models, anaemia independently predicted dyspnoea and reduced exercise capacity.

Anaemia in chronic obstructive pulmonary disease was an independent risk factor for reduced functional capacity. Polycythemia prevalence was low and had no association with worsened outcomes. Further work is required to evaluate the effect of anaemia correction on outcomes in chronic obstructive pulmonary disease.

KEYWORDS: Anaemia, chronic obstructive pulmonary disease, dyspnoea, functional outcomes, haemoglobin, mortality

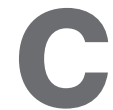
hronic obstructive pulmonary disease (COPD) is highly prevalent and associated with substantial morbidity and mortality. In the USA, an estimated 11.4 million adults were reported to have COPD in 2004 [1]. The forced expiratory volume in one second (FEV1) after bronchodilators has been traditionally viewed as the most accurate predictor of death in these patients [2]. However, COPD produces systemic manifestations not reflected by the FEV1 and, indeed, a number of other factors predictive of COPD-related mortality have been identified. These include malnutrition, poor exercise capacity, increased dyspnoea and presence of comorbidity [3-7]. Recent studies indicate that a composite index consisting of markers of COPD severity (body mass index (BMI), airflow obstruction, dyspnoea and exercise capacity (BODE) index) is a more accurate predictor than FEV1 alone of all-cause and respiratory mortality [8].

Anaemia, a well-recognised comorbidity in many chronic illnesses, is associated with reduced health-related quality of life (HRQL), increased ease $[9,10]$, congestive heart failure [11-13], HIV infection [14, 15], hepatitis-C virus infection [16] and cancer [17]. Anaemia is also associated with disability, impaired physical performance and lower muscle strength in individuals of $\geqslant 65 \mathrm{yrs}$ of age [18].

There is limited information in the current literature describing the distribution of haemoglobin $(\mathrm{Hb})$ and its impact on outcomes in the COPD population. Polycythemia, traditionally thought to be highly prevalent in COPD, occurs less frequently nowadays with more rigorous correction of hypoxaemia [19]. Conversely, recent reports suggest that anaemia in patients with COPD is highly prevalent and associated with increased mortality [20, 21]. Although the association between anaemia and dyspnoea is generally well established [22], the contribution of $\mathrm{Hb}$ to breathlessness and other clinical manifestations in patients with COPD is unknown, and may be of great interest as a potential target for morbidity and mortality in chronic kidney dis-
AFFILIATIONS

*Bay Pines Veterans Affairs Medical Centre (VAMC), Bay Pines, FL,

\#Ortho Biotech Clinical Affairs, LLC, Bridgewater, NJ, and 'St. Elizabeth's Medical Center, Brighton, MA, USA.

CORRESPONDENCE

C. Cote

Dept of Medicine

Respiratory Disease Section Bay Pines VAMC 10,000 Bay Pines Boulevard Bay Pines FL 33744 USA Fax: 17273989549 E-mail: Claudia.Cote@med.va.gov

Received:

October 222006

Accepted after revision: January 082007

SUPPORT STATEMENT

The present study was funded in part by Ortho Biotech Clinical Affairs (Bridgewater, NJ, USA)

\section{STATEMENT OF INTEREST}

Statements of interest for M.D. Zilberberg, S.H. Mody, B. Celli and C. Cote can be found at www.erj.ersjournals.com/misc/ statements.shtml

European Respiratory Journal Print ISSN 0903-1936 Online ISSN 1399-3003 
directed therapy [23]. The purpose of the present study was to determine the prevalence of abnormalities in $\mathrm{Hb}$ levels in patients with COPD attending a pulmonary clinic, as well as to explore the associations between $\mathrm{Hb}$ levels and clinical outcomes.

\section{MATERIALS AND METHODS \\ Study subjects}

The present study was a retrospective analysis of data prospectively collected at one of the sites (Bay Pines Veterans Affairs Medical Centre, Bay Pines, FL, USA) of the multicentre BODE study cohort [8]. COPD was defined by a history of smoking $>20$ pack-yrs and a ratio of FEV1 to forced vital capacity $<0.7$ measured $20 \mathrm{~min}$ after administration of albuterol. Outpatients with a wide range of COPD severity were included. All patients were clinically stable and receiving appropriate therapy for COPD. Exclusion criteria were: 1) an illness other than COPD likely to result in death within $3 \mathrm{yrs}$; 2) asthma (defined as an increase in FEV1 $>15 \%$ above the baseline value or of $200 \mathrm{~mL}$ after administration of a bronchodilator); 3) inability to complete the lung function test or 6-min walking distance (6MWD) test; and 4) myocardial infarction within the preceding 4 months, unstable angina or congestive heart failure (New York Heart Association class III or IV). Full methodology and results from the prospective study have been previously reported elsewhere [8].

\section{Study design}

$\mathrm{Hb}$ data were collected retrospectively, while all other data had been included in the prospective data collection. For each patient, the $\mathrm{Hb}$ value closest in time, prior to or following, BODE testing was collected and analysed. Patients were categorised into three groups according to $\mathrm{Hb}$ thresholds: 1 ) anaemic, with $\mathrm{Hb}$ levels $<13 \mathrm{~g} \cdot \mathrm{dL}^{-1}$ for males and females [24]; 2) polycythemic with $\mathrm{Hb}$ levels $\geqslant 17 \mathrm{~g} \cdot \mathrm{dL}^{-1}$ and $\geqslant 15 \mathrm{~g} \cdot \mathrm{dL}^{-1}$ for males and females, respectively [25]; and 3) normal. Although the $\mathrm{Hb}$ threshold for anaemia in females is defined by the World Health Organization as $<12 \mathrm{~g} \cdot \mathrm{dL}^{-1}$, a threshold of $<13 \mathrm{~g} \cdot \mathrm{dL}^{-1}$ was chosen for all patients in the present study, since the issue of appropriate $\mathrm{Hb}$ threshold for anaemia definition in post-menopausal females remains controversial [26]. In addition, the vast majority (96\%) of patients in the dataset were males. Since the number of polycythemic patients was small and their baseline characteristics and outcomes were not significantly different from the nonpolycythemic group, only the descriptive data on the polycythemia subset are presented. For the analytical portion of the present study, polycythemic patients were included in the group with normal $\mathrm{Hb}$ levels.

Clinical variables evaluated for each group consisted of dyspnoea, exercise capacity, mortality and healthcare resource utilisation. Functional dyspnoea was measured using the Medical Research Council (MRC) dyspnoea scale, a validated instrument that quantitatively assesses the severity of COPDrelated disability [27]. Scores on the MRC dyspnoea scale range $0-4$, with a score of four indicating that the patient is too breathless to leave the house or becomes breathless when dressing or undressing. Exercise capacity was measured according to the $6 \mathrm{MWD}$ test, a standardised, validated test that is a predictor of functional status and death [28]. Mortality and cause of death were determined through family contact followed by review of medical records and death certificates.

Scores on the Charlson comorbidity index (CCI) and the BODE index were also evaluated for each group of patients. The CCI is a validated method for classifying comorbid conditions that can alter the risk of mortality [29] and has been shown to predict mortality [30]. Scores on the CCI range 0-33, with higher scores indicating more coexisting conditions.

\section{Statistical analyses}

Between-group differences in baseline demographic, physiological and disease characteristics were expressed as mean $\pm \mathrm{SD}$ values. The between-group differences were calculated using a two-sided paired t-test or Chi-squared statistic where appropriate. A p-value $<0.05$ was considered statistically significant. Linear regression analyses controlling for age, FEV1, CCI and BMI were performed to identify the independent association of anaemia with the MRC dyspnoea scale and the 6MWD test. Median survival and the overall probability of survival between anaemic and nonanaemic patients were calculated using Kaplan-Meier estimates. A logistic regression analysis and a Cox proportional hazards model were run to adjust the estimate of $\mathrm{Hb}$ association with mortality for age, $\mathrm{CCI}$ and BODE index.

\section{RESULTS}

\section{Patient characteristics}

Of the 683 patients in the dataset (656 males, 27 females; mean \pm SD age $67 \pm 9 \mathrm{yrs}), 677$ were eligible for analysis $(650$ males, 27 females; $70 \pm 9 \mathrm{yrs}$ ). The remaining 6 male patients (74 $\pm 5 \mathrm{yrs})$ were excluded due to missing $\mathrm{Hb}$ values. The mean \pm SD $\mathrm{Hb}$ for all patients was $14.4 \pm 1.7 \mathrm{~g} \cdot \mathrm{dL}^{-1}$. Anaemia was present in $116(17.1 \%)$ patients, while polycythemia was recorded in $40(5.9 \%)$ patients. Applying the $\mathrm{Hb}$ threshold of $13 \mathrm{~g} \cdot \mathrm{dL}^{-1}$, as opposed to $12 \mathrm{~g} \cdot \mathrm{dL}^{-1}$, for anaemia definition among females in the present study resulted in potential misclassification of three subjects, whose $\mathrm{Hb}$ values were $\geqslant 12$ $<13 \mathrm{~g} \cdot \mathrm{dL}^{-1}$. Mean $\mathrm{Hb}$ levels for anaemic and nonanaemic patients were $11.8 \pm 1.0 \mathrm{~g} \cdot \mathrm{dL}^{-1}$ and $15.0 \pm 1.2 \mathrm{~g} \cdot \mathrm{dL}^{-1}$, respectively $(\mathrm{p}<0.0001)$. There was no difference in the mean $\mathrm{Hb}$ between patients receiving supplemental oxygen and those who did not receive it $\left(14.4 \pm 1.8 \mathrm{~g} \cdot \mathrm{dL}^{-1}\right.$ and $14.5 \pm 1.6 \mathrm{~g} \cdot \mathrm{dL}^{-1}$, respectively; $\mathrm{p}=0.49$ ), and there was no correlation between arterial oxygen tension and $\mathrm{Hb}$ (Pearson $\mathrm{r}=-0.06$ ). Overall, anaemic patients were significantly older and more chronically ill than their nonanaemic counterparts, as manifested by significantly higher CCI and BODE index scores (table 1). Conversely, except for higher mean $\mathrm{Hb}$ and $\mathrm{BMI}$ in the group with polycythemia, there were no significant differences in the baseline characteristics or outcome measures between polycythemic and nonpolycythemic groups (table 2).

\section{Dyspnoea and functional impairment}

Dyspnoea and functional status differed significantly between anaemic and nonanaemic patients. Mean MRC values were significantly higher $(2.8 \pm 0.9$ versus $2.6 \pm 0.8 ; \mathrm{p}=0.04)$ and mean $6 \mathrm{MWD}$ was significantly shorter $(265 \pm 122 \mathrm{~m}$ versus $325 \pm 124 \mathrm{~m}$; $\mathrm{p}<0.0001)$ in anaemic compared with nonanaemic patients (table 1). When MRC and 6MWD were evaluated as a function of $\mathrm{Hb}$ ranges, there was a linear relationship between declining $\mathrm{Hb}$ and increasing dyspnoea and functional impairment 


\begin{tabular}{|c|c|c|c|}
\hline Variable & Anaemic & Nonanaemic & p-value ${ }^{\#}$ \\
\hline Subjects $n$ & 116 & 561 & \\
\hline Age yrs & $72.8 \pm 9.3$ & $69.5 \pm 8.8$ & 0.0003 \\
\hline Haemoglobin $\mathbf{g} \cdot \mathrm{dL}^{-1}$ & $11.8 \pm 1.0$ & $15.0 \pm 1.2$ & $<0.0001$ \\
\hline FEV $1 \%$ pred & $43.2 \pm 17.0$ & $42.1 \pm 17.3$ & 0.53 \\
\hline $\mathrm{Pa}, \mathrm{O}_{2} \mathrm{mmHg}$ & $72.1 \pm 13.3$ & $71.9 \pm 11.9$ & 0.87 \\
\hline MRC dyspnoea scale & $2.8 \pm 0.9$ & $2.6 \pm 0.8$ & 0.04 \\
\hline $\mathrm{BMI} \mathbf{k g} \cdot \mathrm{m}^{-2}$ & $27.1 \pm 6.7$ & $26.3 \pm 5.8$ & 0.22 \\
\hline 6MWD m & $265.4 \pm 122.1$ & $325.1 \pm 124.4$ & $<0.0001$ \\
\hline $\mathrm{CCl}$ & $6.5 \pm 3.5$ & $4.8 \pm 2.4$ & $<0.0001$ \\
\hline BODE index & $5.3 \pm 2.6$ & $4.7 \pm 2.4$ & 0.01 \\
\hline \multicolumn{4}{|c|}{ 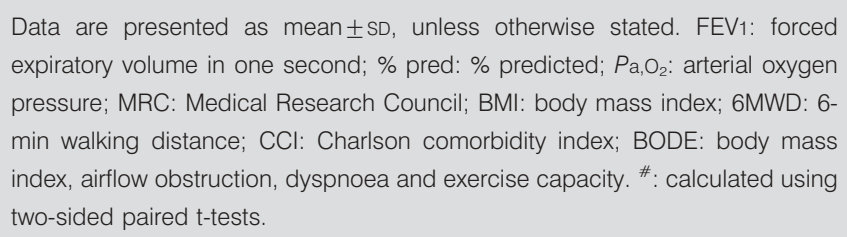 } \\
\hline
\end{tabular}

(figs 1 and 2). In regression models controlling for age, FEV1, $\mathrm{CCI}$ and BMI, anaemia remained an independent predictor of increased MRC and reduced 6MWD (table 3).

\section{Mortality}

A total of $53(46.8 \%)$ anaemic and $187(31.2 \%)$ nonanaemic patients died $(\mathrm{p}=0.01)$ during the study (mean follow-up $34 \pm 22$ months and $37 \pm 22$ months, respectively; $p=0.15)$. Age $(\mathrm{p}<0.01), \mathrm{Hb}(\mathrm{p}<0.01), \mathrm{CCI}(\mathrm{p}<0.0001)$ and BODE score

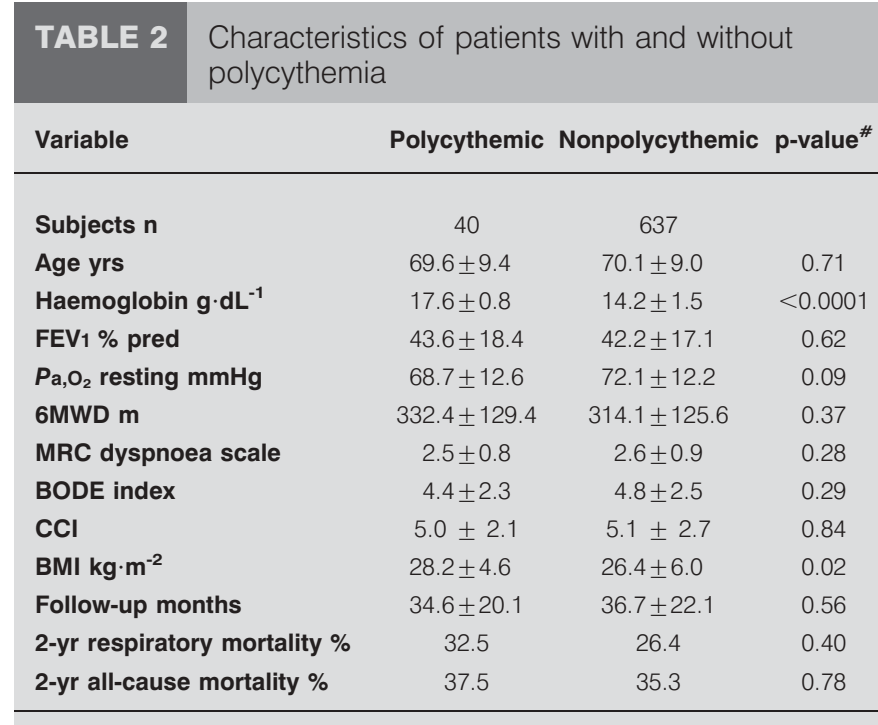

Data are presented as mean $\pm \mathrm{SD}$, unless otherwise stated. FEV 1 : forced expiratory volume in one second; \% pred: \% predicted; $\mathrm{Pa}_{\mathrm{a}} \mathrm{O}_{2}$ : arterial oxygen pressure; 6MWD: 6-min walking distance; MRC: Medical Research Council BODE: body mass index, airflow obstruction, dyspnoea and exercise capacity CCI: Charlson comorbidity index; BMI: body mass index. "\#: calculated using Chi-squared tests for mortality and two-sided paired t-tests for all other variables.

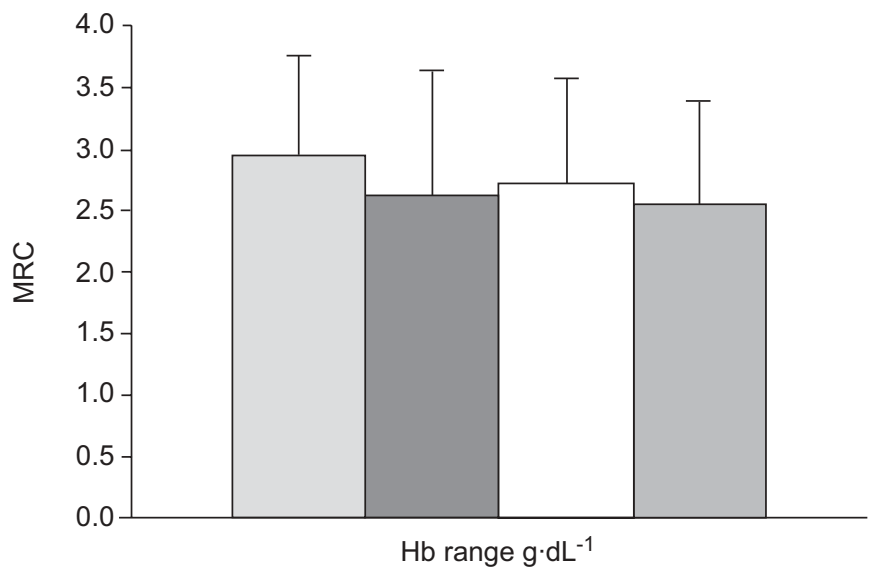

FIGURE 1. Relationship between haemoglobin $(\mathrm{Hb})$ level and the Medical Research Council (MRC) dyspnoea scale. $\quad:<12 \mathrm{~g} \cdot \mathrm{dL}^{-1}(\mathrm{n}=49) ; \quad \square: \geqslant 12-$ $<13 \mathrm{~g} \cdot \mathrm{dL}^{-1}(\mathrm{n}=67) ; \square: \geqslant 13-<14 \mathrm{~g} \cdot \mathrm{dL}^{-1}(\mathrm{n}=127) ; \square: \geqslant 14 \mathrm{~g} \cdot \mathrm{dL}^{-1}(\mathrm{n}=434)$.

$(\mathrm{p}<0.0001)$ differed significantly between survivors and nonsurvivors (table 4). The median survival was 49 months in anaemic patients and 74 months in nonanaemic patients $(\mathrm{p}<0.01$; fig. 3$)$. While the BODE index and the CCI were significantly associated with increased mortality in both the Cox model and the multivariate logistic regression analysis (table 5), anaemia was not identified as a significant independent predictor of mortality.

\section{DISCUSSION}

In the current study, anaemia was prevalent (17\%) among patients with COPD attending a Veterans Affairs pulmonary clinic and was independently associated with increased dyspnoea and reduced exercise capacity as measured by the $6 \mathrm{MWD}$. In contrast, there was a very low prevalence of polycythemia and, when present, it carried no clinical relevance.

Although anaemia has been associated with dyspnoea and reduced exercise capacity in patients with pre-dialysis chronic

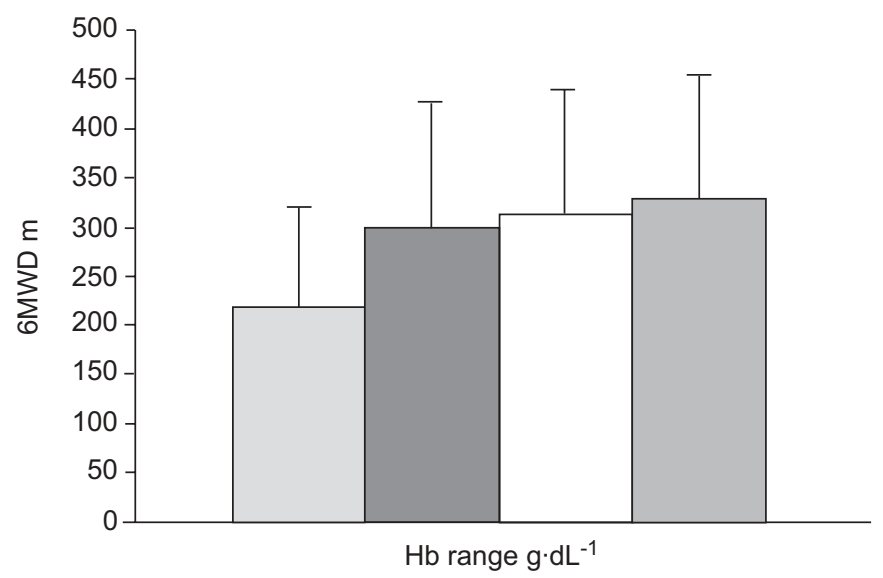

FIGURE 2. Change in the 6-min walking distance (6MWD) test as a function of haemoglobin $(\mathrm{Hb})$ level. $\square:<12 \mathrm{~g} \cdot \mathrm{dL}^{-1}(\mathrm{n}=49) ; \quad \square: \geqslant 12-<13 \mathrm{~g} \cdot \mathrm{dL}^{-1} \quad(\mathrm{n}=67)$; $\square: \geqslant 13-<14 \mathrm{~g} \cdot \mathrm{dL}^{-1}(\mathrm{n}=127) ; \quad: \geqslant 14 \mathrm{~g} \cdot \mathrm{dL}^{-1}(\mathrm{n}=434)$. 


\begin{tabular}{|c|c|c|c|c|c|c|}
\hline \multirow[t]{3}{*}{ TABLE 3} & \multicolumn{6}{|c|}{$\begin{array}{l}\text { Multivariate regression analysis for risk of } \\
\text { dyspnoea and functional impairment }\end{array}$} \\
\hline & \multicolumn{3}{|c|}{ MRC dyspnoea scale } & \multicolumn{3}{|c|}{ 6MWD test } \\
\hline & $\beta$-coefficient & SE & $p$-value & $\beta$-coefficient & SE & $\mathrm{p}$-value \\
\hline Age & 0.008 & 0.004 & 0.0199 & -1.36 & 0.52 & 0.0097 \\
\hline Haemoglobin & -0.036 & 0.018 & 0.0479 & 8.61 & 2.68 & 0.0014 \\
\hline FEV1 \% pred & -0.023 & 0.002 & $<0.0001$ & 2.42 & 0.26 & $<0.0001$ \\
\hline $\mathrm{CCl}$ & 0.041 & 0.012 & 0.0006 & -11.14 & 1.79 & $<0.0001$ \\
\hline BMI & 0.007 & 0.005 & 0.1962 & -0.02 & 0.76 & 0.98 \\
\hline
\end{tabular}

kidney disease [31], cancer [32] and heart failure [33], the present study is the first to demonstrate that anaemia is a strong independent predictor of dyspnoea and reduced exercise capacity in patients with COPD. The exact mechanism by which anaemia may decrease exercise capacity is complex and not fully understood. However, oxygen carrying capacity depends directly upon the level of haemoglobin and oxygen delivery is crucial for the maintenance of oxidative metabolism. Anaemia may result in limited oxygen supply and early onset of anaerobic threshold, with the consequent increase in ventilatory drive. Given the decreased ventilatory reserve among patients with COPD, the accompanying increased ventilatory demand may result in dyspnoea.

In the current study, polycythemia was present in $6 \%$ of the COPD patients and did not appear to be associated either with an increased COPD severity or with altered outcomes. The use of long-term oxygen therapy has been reported to control polycythemia in patients with COPD [19]. Thus, the fact that more than one third of the patients received supplemental oxygen therapy may at least partially account for the low prevalence of polycythemia observed in the present study.

The prevalence of anaemia identified in the present study $(17 \%)$, while somewhat higher than the $10.6 \%$ prevalence

\begin{tabular}{|c|c|c|c|}
\hline TABLE 4 & $\begin{array}{l}\text { Significant differe } \\
\text { between survivors }\end{array}$ & $\begin{array}{l}\text { patient char } \\
\text { onsurvivors }\end{array}$ & eristics \\
\hline Variable & Survivors & Nonsurvivors & p-value \\
\hline Subjects $\mathrm{n}$ & 437 & 240 & \\
\hline Age yrs & $69.4 \pm 9.0$ & $71.3 \pm 8.8$ & 0.0086 \\
\hline $\begin{array}{l}\text { Haemoglobin } \\
\text { g. } \mathrm{dL}^{-1}\end{array}$ & $14.6 \pm 1.5$ & $14.2 \pm 1.9$ & 0.0021 \\
\hline $\mathrm{CCl}$ & $4.6 \pm 2.4$ & $6.1 \pm 2.9$ & $<0.0001$ \\
\hline BODE index & $4.0 \pm 2.0$ & $6.3 \pm 2.5$ & $<0.0001$ \\
\hline
\end{tabular}

Data are presented as mean $\pm \mathrm{SD}$, unless otherwise stated. CCl: Charlson comorbidity index; BODE: body mass index, airflow obstruction, dyspnoea and exercise capacity index. ${ }^{*}$ : calculated using a two-sided paired t-test.

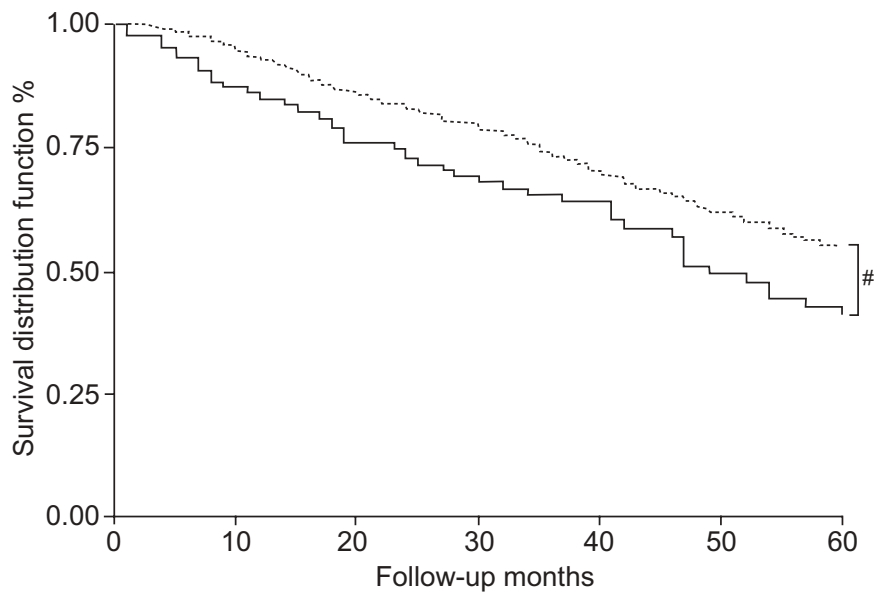

FIGURE 3. Kaplan-Meier probability of overall survival in anaemic $(-)$ and nonanaemic patients $(\cdots \cdots)$. The number of anaemic and nonanaemic patients at baseline was 116 and 561, respectively. During follow-up, the predicted number of anaemic patients was 99, 75, 53, 49, 31 and 20 at 10, 20, 30, 40, 50 and 60 months, respectively. During follow-up, the predicted number of nonanaemic patients was $528,397,292,217,150$ and 101 at 10, 20, 30, 40, 50 and 60 months, respectively. \# $\mathrm{p}=0.0091$.

observed among community-dwelling elderly [26], is similar to that reported in recent studies of COPD patients [20, 21]. In general, anaemic patients were somewhat older and carried a higher physiological dysfunction burden, as evidenced by a higher mean CCI and BODE index scores. Even after adjusting for the unequal disease burden distribution, anaemia was strongly and independently associated with worse MRC dyspnoea scores and reduced 6MWD, indicating a possible link between $\mathrm{Hb}$ and functional status.

Anaemia of inflammation or anaemia of chronic disease [34] are likely to play a major role in the setting of COPD, particularly since it has been identified as the cause of one third of all anaemia cases observed in the community-dwelling elderly population [26]. One recent study [20] has documented that anaemia in COPD is, at least in part, due to inflammation and resistance to elevated levels of serum erythropoietin. This

\begin{tabular}{ll} 
TABLE 5 & $\begin{array}{l}\text { Multivariate logistic regression analysis for risk of } \\
\text { death }\end{array}$ \\
Parameter & OR $\left.^{\mathbf{*}} \mathbf{( 9 5 \%} \mathbf{C I}\right)$ \\
\hline Age & $0.994(0.972-1.017)$ \\
Haemoglobin & $0.983(0.880-1.099)$ \\
CCI & $1.234(1.143-1.332)$ \\
BODE index & $1.535(1.412-1.668)$ \\
\hline
\end{tabular}

OR: odds ratio; $\mathrm{Cl}$ : confidence interval; $\mathrm{CCl}$ : Charlson comorbidity index BODE: body mass index, airflow obstruction, dyspnoea and exercise capacity index. ${ }^{\#}$ : the increase in $\mathrm{OR}$ is calculated per $1 \mathrm{yr}$ of age, per $1 \mathrm{~g} \cdot \mathrm{dL}^{-1}$ of haemoglobin and per 1 point of $\mathrm{CCl}$ and BODE index. 
is not surprising, given the systemic inflammatory state that has been documented in patients with COPD [35]. However, more research is needed to gain a better understanding of the potential causes of anaemia in COPD.

Aetiology notwithstanding, anaemia in COPD has been shown to be associated with adverse outcomes in recent clinical studies. In a study by CHAMBELLAN et al. [21] of 2,524 patients with severe COPD receiving long-term oxygen therapy, anaemia was associated with a lower long-term survival rate, a higher hospital admission rate and a longer duration of hospital stay compared with nonanaemic patients. The relative risk of death decreased by $14 \%$ with every $5 \%$ increase in haematocrit $(\mathrm{p}<0.001)$ and haematocrit was the strongest predictor of mortality next to age. In addition, haematocrit was inversely correlated with both the rate $(r=-0.091 ; p=0.001)$ and duration $(\mathrm{r}=-0.095 ; \mathrm{p}<0.001)$ of hospitalisation. In contrast to the study by CHAMBELLAN et al. [21], the current analyses did not confirm a significant independent association between anaemia and survival. This is perhaps best explained by the fact that the study by CHAMBELLAN et al. [21] represents patients with more severe COPD compared with those in the present cohort. Additionally, comorbidity or COPD severity scores, such as the BODE index, were not included as covariates. It is likely that these tools already incorporate factors that may be associated with anaemia and thereby dilute the predictive power of anaemia per se on mortality. Future studies, however, need to continue to examine the association of anaemia with worsened outcomes, including mortality, in patients with COPD.

The relationship between anaemia and adverse clinical outcomes in patients with COPD is consistent with findings in other chronic disease states. Increased morbidity, mortality and decreased HRQL are well established in chronic kidney disease [10, 36], cancer [17, 32, 37], congestive heart failure [11, 13] and HIV infection [12, 14] with concomitant anaemia. Furthermore, numerous studies have demonstrated that correction of anaemia improves outcomes in these populations, resulting in improved functional and exercise capacity, reduced dyspnoea and improved quality of life [14, 37]. In COPD, several small studies have suggested how correction of anaemia may affect outcomes in COPD. SCHÖNHOFER et al. [38] demonstrated that correction of anaemia with blood transfusions among 20 patients with severe COPD significantly reduced disease-related elevations in minute ventilation and work of breathing, suggesting that anaemia correction may be beneficial in alleviating dyspnoea and improving exercise capacity. In a separate study, SCHÖNHOFER et al. [39] demonstrated that among five patients with severe anaemia, successful treatment of anaemia resulted in an increased ability to wean patients from mechanical ventilation. While the current study did not attempt to answer the question of how anaemia correction affects outcomes, the results support the hypothesis that anaemia is associated with adverse consequences in patients with COPD. Although anaemia, a possible systemic manifestation of COPD, may be an epiphenomenon identifying sicker patients, it is reasonable to hypothesise, based on others' and the present authors' findings, that correction of anaemia may result in improved outcomes. This hypothesis requires rigorous testing in a well-designed clinical trial.
The current study is limited by its retrospective design and is, therefore, subject to the general biases inherent in such designs. For example, the $\mathrm{Hb}$ data, which were incomplete or unavailable in the prospectively collected dataset, had to be retrospectively collected for the present analysis. As a result, the temporal relationship between $\mathrm{Hb}$ values and other variables is not consistent. The present authors attempted to minimise the effect of a random $\mathrm{Hb}$ selection on the outcomes of interest by choosing the $\mathrm{Hb}$ value temporally closest to the BODE index evaluation. This, however, does not eliminate the cross-sectional nature of the relationship of $\mathrm{Hb}$ and MRC and $6 \mathrm{MWD}$ outcomes, although the temporal relationship of $\mathrm{Hb}$ measurement and mortality end-point is preserved. Another potential limitation of the present study is that most patients were male; thus, the results may not be generalisable to females. However, other studies [40] have demonstrated adverse effects of anaemia among elderly females, although not specifically in the setting of COPD. Likewise, because elderly veteran patients have been shown to have a poorer health status and higher disease burden than nonveterans [41], these data may not be generalisable to patients with COPD seen outside of a Veterans Affairs pulmonary clinic. Nevertheless, the current study serves as a basis for evaluating the relationship between anaemia and clinical and functional outcomes in patients with COPD.

Although no inference of causality is possible, the present results suggest that anaemia is prevalent and associated with poor clinical and functional outcomes in patients with chronic obstructive pulmonary disease, and provide support for the evaluation and monitoring of anaemia in these patients. Since inflammation and erythropoietin suppression are likely to be at least in part responsible for anaemia in the chronic obstructive pulmonary disease population, future study designs need to incorporate evaluation of inflammatory mediators and their relationship to anaemia in chronic obstructive pulmonary disease. Prospective studies and controlled trials are warranted to confirm the present authors' observations and to test the hypothesis that correction of anaemia can improve these clinical outcomes of patients with chronic obstructive pulmonary disease.

\section{REFERENCES}

1 American Lung Association. Chronic obstructive pulmonary disease (COPD) fact sheet. www.kintera.org/site/ pp.asp?c $=$ dvLUK9O0E\&b $=35020$. Date last accessed: December 11, 2006. Date last updated: August, 2006.

2 Anthonisen NR, Wright EC, Hodgkin JE. Prognosis in chronic obstructive pulmonary disease. Am Rev Respir Dis 1986; 133: 14-20.

3 Almagro P, Calbo E, Ochoa de Echagüen A, et al. Mortality after hospitalization for COPD. Chest 2002; 121: 1441-1448.

4 Gerardi DA, Lovett L, Benoit-Connors ML, Reardon JZ, ZuWallack RL. Variables related to increased mortality following out-patient pulmonary rehabilitation. Eur Respir J 1996; 9: 431-435.

5 Hersh CP, DeMeo DL, Al-Ansari E, et al. Predictors of survival in severe, early onset COPD. Chest 2004; 126: 1443-1451. 
6 Incalzi RA, Fuso L, De Rosa M, et al. Co-morbidity contributes to predict mortality of patients with chronic obstructive pulmonary disease. Eur Respir J 1997; 10: 2794-2800.

7 Landbo C, Prescott E, Lange P, Vestbo J, Almdal TP. Prognostic value of nutritional status in chronic obstructive pulmonary disease. Am J Respir Crit Care Med 1999; 160: 1856-1861.

8 Celli BR, Cote CG, Marin JM, et al. The body-mass index, airflow obstruction, dyspnoea, and exercise capacity index in chronic obstructive pulmonary disease. $N$ Engl J Med 2004; 350: 1005-1012.

9 IV. NKF-K/DOQI clinical practice guidelines for anemia of chronic kidney disease: update 2000. Am J Kidney Dis 2001; 37: Suppl. 1, S182-S238.

10 Silberberg JS, Rahal DP, Patton DR, Sniderman AD. Role of anemia in the pathogenesis of left ventricular hypertrophy in end-stage renal disease. Am J Cardiol 1989; 64: 222-224.

11 Horwich TB, Fonarow GC, Hamilton MA, MacLellan WR, Borenstein J. Anemia is associated with worse symptoms, greater impairment in functional capacity and a significant increase in mortality in patients with advanced heart failure. J Am Coll Cardiol 2002; 39: 1780-1786.

12 McMurray JJV. What are the clinical consequences of anemia in patients with chronic heart failure? J Card Fail 2004; 10: Suppl. 1, S10-S12.

13 Sharma R, Francis DP, Pitt B, Poole-Wilson PA, Coats AJ, Anker SD. Haemoglobin predicts survival in patients with chronic heart failure: a substudy of the ELITE II trial. Eur Heart J 2004; 25: 1021-1028.

14 Belperio PS, Rhew DC. Prevalence and outcomes of anemia in individuals with human immunodeficiency virus: a systematic review of the literature. Am I Med 2004; 116: Suppl. 7A, S27-S43.

15 Volberding $P$. The impact of anemia on quality of life in human immunodeficiency virus-infected patients. J Infect Dis 2002; 185: Suppl. 2, S110-S114.

16 Pockros PJ, Shiffman ML, Schiff ER, et al. Epoetin alfa improves quality of life in anemic HCV-infected patients receiving combination therapy. Hepatology 2004; 40: $1450-1458$

17 Caro JJ, Salas M, Ward A, Goss G. Anemia as an independent prognostic factor for survival in patients with cancer: a systemic, quantitative review. Cancer 2001; 91: 2214-2221.

18 Penninx BW, Pahor M, Cesari M, et al. Anaemia is associated with disability and decreased physical performance and muscle strength in the elderly. J Am Geriatr Soc 2004; 52: 719-724.

19 Zielinski J. Effects of long-term oxygen therapy in patients with chronic obstructive pulmonary disease. Curr Opin Pulm Med 1999; 5: 81-87.

20 John M, Hoernig S, Doehner W, Okonko DD, Witt C, Anker SD. Anemia and inflammation in COPD. Chest 2005; 127: 825-829.

21 Chambellan A, Chailleux E, Similowski T, ANTADIR Observatory Group. Prognostic value of hematocrit in patients with severe COPD receiving long-term oxygen therapy. Chest 2005; 128: 1201-1208.

22 Mansen TJ, McCance KL, Parker-Cohen PD. Alterations of erythrocyte function. In: McCance KL, Huether SE, eds.
Pathophysiology. The Biologic Basis for Disease in Adults and Children. 2nd Edn. St. Louis, Mosby-Year Book Inc., 1994; pp. 860-877.

23 Similowski T, Agusti A, MacNee W, Schonhofer B. The potential impact of anaemia of chronic disease in COPD. Eur Respir J 2006; 27: 390-396.

24 World Health Organization. Nutritional anemias: report of a WHO scientific group. WHO Technical Report Series 405. Geneva, World Health Organization, 1968; pp. 1-37.

25 Kasper DL, Braunwald E, Fauci AS, et al., eds. Harrison's Principles of Internal Medicine. 16th Edn. McGraw-Hill's Access Medicine. www.accessmedicine.com/content.aspx? $\mathrm{aID}=58150$. Date last accessed: December 11, 2006.

26 Guralnik JM, Ersshler WB, Schrier SL, Picozzi VJ. Anemia in the elderly: a public health crisis in hematology. Hematology Am Soc Hematol Educ Program 2005; 1: 528-532.

27 Bestall JC, Paul EA, Garrod R, Garnham R, Jones PW, Wedzicha JA. Usefulness of the Medical Research Council (MRC) dyspnoea scale as a measure of disability in patients with chronic obstructive pulmonary disease. Thorax 1999; 54: 581-586.

28 Pinto-Plata VM, Cote C, Cabral H, Taylor J, Celli BR. The 6min walk distance: change over time and value as a predictor of survival in severe COPD. Eur Respir J 2004; 23: 28-33.

29 Charlson ME, Pompei P, Ales KL, MacKenzie CR. A new method of classifying prognostic comorbidity in longitudinal studies: development and validation. J Chronic Dis 1987; 40: 373-383.

30 Charlson M, Szatrowski TP, Peterson J, Gold J. Validation of a combined comorbidity index. J Clin Epidemiol 1994; 47: 1245-1251.

31 Lim VS, DeGowin RL, Zavala D, et al. Recombinant human erythropoietin treatment in pre-dialysis patients. A double-blind placebo-controlled trial. Ann Intern Med 1989; 110: 108-114.

32 Dudgeon DJ, Lertzman M, Askew GR. Physiological changes and clinical correlations of dyspnea in cancer outpatients. J Pain Symptom Manage 2001; 21: 373-379.

33 Mancini DM, Katz SD, Lang CC, LaManca J, Hudaihed A, Androne AS. Effect of erythropoietin on exercise capacity in patients with moderate to severe chronic heart failure. Circulation 2003; 107: 294-299.

34 Weiss G, Goodnough LT. Anemia of chronic disease. N Engl J Med 2005; 352: 1011-1023.

35 Pinto-Plata VM, Mullerova $\mathrm{H}$, Toso JF, et al. C-reactive protein in patients with COPD, control smokers, and nonsmokers. Thorax 2006; 61: 23-28.

36 Abramson JL, Jurkovitz CT, Vaccarino V, Weintraub WS McClellan W. Chronic kidney disease, anemia, and incident stroke in a middle-aged, community-based population: the ARIC study. Kidney Int 2003; 64: 610-615.

37 Cella D, Zagari MJ, Vandoros C, Gagnon DD, Hurtz HJ, Nortier JW. Epoetin alfa treatment results in clinically significant improvements in quality of life in anemic cancer patients when referenced to the general population. J Clin Oncol 2003; 21: 366-373.

38 Schönhofer B, Wenzel M, Geibel M, Köhler D. Blood transfusion and lung function in chronically anemic patients with severe chronic obstructive pulmonary disease. Crit Care Med 1998; 26: 1824-1828. 
39 Schönhofer B, Böhrer H, Köhler D. Blood transfusion facilitating difficult weaning from the ventilator. Anaesthesia 1998; 53: 181-184.

40 Chaves PH, Ashar B, Guralnik JM, Fried LP. Looking at the relationship between hemoglobin concentration and prevalent mobility difficulty in older women.
Should the criteria currently used to define anemia in older people be reevaluated? I Am Geriatr Soc 2002; 50: 1257-1264.

41 Selim AJ, Berlowitz DR, Fincke G, et al. The health status of elderly veteran enrollees in the Veterans Health Administration. J Am Geriatr Soc 2004; 52: 1271-1276. 